\title{
Self-Management as a Predictor of Student Performance
}

\author{
Elena Petanova \\ Faculty of Psychology \\ Saint Petersburg State University \\ St. Petersburg, Russia \\ E-mail: e.petanova@ spbu.ru
}

\author{
Radostina Stoyanova \\ Department of Slavic Philology \\ Saint Petersburg State University \\ St. Petersburg, Russia \\ Department of Foreign Languages \\ University of Economics - Varna, College of tourism \\ 77 Kniaz Boris Blvd., 9002 Varna, Bulgaria \\ E-mail: r.stoyanova@spbu.ru
}

\begin{abstract}
This article reviews the study of predictors in fist-year students' academic performance with its index being calculated on the basis of their interim academic success assessments on two fields of study. The self-management capacity was determined by the methods of $N$. Peisakhov, and the sampling included 55 first-year students of the economic faculty of St-Petersburg State University (40 women and 15 men). The quantitative analysis was conducted using the descriptive statistics and regression analysis. The study revealed that the self-management operation 'forecasting' can be considered the predictor of student performance.
\end{abstract}

Keywords-students; student performance; self-management operations; academic performance predictors

\section{INTRODUCTION}

Contemporary theorists of higher vocational education psychology believe training of university students is implying an active process of professionally important knowledge deepening and professional skills development. These specified goals can be pursued in the setting of students' productive self-management in their academic performance and interactions with subjects of the university learning environment.

Achievement of the successful learning in academic environment, as set out in the doctoral thesis of Y.D. Yankulova (2014), and of trainee individuals' full cognitive and individual potential, requires a specific learning environment wherein it is possible to attain the sustainable development of cognitive structures and knowledge systems, as well as of the skill to organize, assess and manage activities in process of learning. This would help achieve greater efficiency in the cognitive process, a significant change in the personality organization and the better selfmanagement $[1,5]$. The problem of development of more efficient technologies optimizing the process of teaching and raising the level of student performance today becomes more obvious to many university professors and psychologists in the higher education field.
The scope of search for the psychological predictors in the student performance is constantly expanding. For instance, psychologists worldwide are beginning to have a closer look at different aspects of self-management capacity in professional education for the purpose of better student performance [2]. Russian psychologists have identified that the self-management capacity is the prerequisite of students' educational and professional successfulness [3]. Respondents in the cited research were psychologist students, however, it is necessary to clarify whether the obtained interrelatedness can be considered distinctive for students in other educational directions also.

\section{THEORETICAL BACKGROUND TO THE RESEARCH}

In Russia's psychological science the problem of selfmanagement is widely presented in case studies of Kazanbased psychology school and takes its origin in the scientific efforts of N.M. Peisakhov, who sought to distinguish in the fundamental concept of individual's self-management the practical value and, in particular, to study students' selfmanagement capacity in their learning environment [4].

For Peisakhov, the self-management presents a task-oriented self-modification or control by the individual of various forms of his individual activity-communicating, behaviour, activities and experiences. The scholar outlines also that self-management is essentially a creative process pertaining to the formation of a certain recency, with the necessity for setting new goals, looking for original solutions and resources to achieve goals. This particular element of creativeness and novelty forms the critical criterion separating the concepts of self-management and selfregulation - the latter offers the process that also includes changes, accomplished, however, within the limits of predetermined rules, norms and stereotypes. According to Peisakhov, the self-regulation is an act succeeding the selfmanagement and bases on it. While the self-regulation function presents assimilation of the patterns previously developed through the self-regulation. Consequently, Peisakhov's concept treats self-management and selfregulation as "two sides of the individual's performance, the 
dialectical unity of changeable and sustainable in the ongoing development of individual's subjective world" [4].

The fundamental rational of Peisakhov's theory is that the self-management capacity appears only when there is a meaningful need. Such need occurs in circumstances when conventional ways and means of activity are vain, when the individual experiences frustration from his goings and actions. In such case the individual, while investigating known practices and ways of behaving, begins to recognize the importance of getting down to the development of an algorithm of managing his activities intended to achieve meaningful goals, namely the self-management.

Among the most significant psychological studies addressing the interconnections between the selfmanagement capacity and students performance, must be mentioned the studies conducted in line with Peisakhov's concept [5], [6].

It has been also established that in the process of student's development, being the subject of the study, his self-management capacity was gradually improving. Moreover, has been identified the high-level relationship of self-management with the internal locus of control and that the extent of general self-management capacity can contribute to a higher estimation along the examination control [3].

The information mentioned in the text, reflecting the relationship between the self-management capacity and academic success, presents a prerequisite for considering the self-management capacity as a constituent of the resourcebased array of student performance.

This hypothesis became a basis for the empirical study.

\section{CORRELATION STUDY ON SELF-MANAGEMENT STRATEGIES AND STUDENT PERFORMANCE}

The sample respondents included 55 first-year students of the economic faculty of SPbGU in the age group of 17-19 years (40 women and 15 men).

Psychodiagnostics was run at the hand-on seminar on psychology. Its target was the individually meaningful goal of developing self-comprehension and the identification of major personal attributes (at the first stage of adjustment to university studies). Completion of the questionnaire was carried out at a comfortable individual pace with the overall completion time limited to one academic hour.

The respondent students were concerned with in psychodiagnostics of their self-managements capacity; they also gave consent to the use of the findings in scientific research work.

\section{Psychodiagnostics Methodology}

The "Self-Management Capacity" questionnaire of N. Peisakhov was used as the psychodiagnostics tool. This technique was developed by N.M. Peisakhov in the laboratory of psychological problems of the higher school of Kazan State University. The test offers 48 assertions; if the respondent agrees with an assertion he tags '+', or '-' if disagrees. The respondents gave their answers in the reply forms. The results were processed by rowwise count of 'yes' and 'no' answers and totaled. Their general score was correlated to the psychodiagnostic scale. Respondents' gender identity is being taken into account.

While interpreting the obtained results the researchers took into consideration that the results positioning on the scale righthand marked the presence of the self-management system with a probability, however, of excessive prudence and rationality. The results in the scale's opposite side showed the respondent was likely to lack an integrated system of self-management and just some of its elements were pronounced.

The self-management capacity appears when usual activity methods and interpersonal relationship become ineffective and do not produce desired results. In such case the individual applies new methods and ways, but when they fail, the need arises to analyse the situation, promote fresh targets so to change the situation. At this point the development of self-management system, which, according to N.M. Peiskhov, includes eight phases, begins:

- Analysis of contradictions or orientation in the situation - the individual develops his own psychologic situation model and investigates it round about;

- Forecasting - creation by the individual of a forecast model based on his past and current experiences, and on the study of antecedent and present contradictions;

- Goal setting - forming of the subject pattern of the targeted and needed. Forecasting underlies the goalsetting. This is the transfer from the assumption about the possibility in principle to make changes to the assumption about probable outcomes.

- Planning - the individual creates the pattern of consummation means and the sequence of their utilization;

- Quality assessment - the individual must answer the question what should be the criteria allowing assess the success in implementation of one or other strategy;

- Decision-making-moving from plans and reflections to practical steps;

- Self-check-collection of information on how the delivery of the strategy in actual communication and activities is going;

- Adjustment - alteration of actual doings, behavior, communicating, experiences, and of the selfmanagement system itself.

\section{Mathematical and Statistical TeChnOlOGy of DATA PROCESSING}

Statistical processing of the empirical research findings employed the parametric methods of mathematic analysis, since the distribution of received data did not statistically 
definitely deviate from normal. Subsequenlty, 'the regression analysis' was carried out. Usable software: Microsoft Office Excel 2010; Statistica 9; SPSS 23.0.

The student performance index is built on the sum of examination scores in two major fields "Table I".

TABLE I. Statistics On the First-year StUdents Performance (M-MeAn VALUE; S.D. - StandaRd DEVIATION)

\begin{tabular}{|l|c|c|c|}
\hline \multirow{2}{*}{\multicolumn{1}{|c|}{ Discipline }} & \multicolumn{2}{|c|}{ Men } & Women \\
\cline { 2 - 4 } & $\boldsymbol{M}$ & S.D. & $\boldsymbol{M}$ \\
\hline Mathematical analysis & 6.2 & 1.4 & 6.4 \\
\hline Statistics in economics & 7.2 & 1.5 & 7.1 \\
\hline Average & 6.7 & 1.1 & 6.8 \\
\hline
\end{tabular}

Gender differences in the academic performance have not been found, accordingly all the indices hereinafter will be presented without the gender-based accentuation.

\section{FORMATION OF STUdENTS' SELF-MANAGEMENT STRATEGIES}

The "Self-Management Capacity" questionnaire of N. Peisakhov technology provided the eight-scale data, presenting in total the common self-management capacity value "Table II". The extent of each self-management strategy was assessed in terms of standard criteria developed by the author of the technology, and positioned in one of three intensity categories - average, below the average, above the average.

TABLE II. STATISTICS ON THE FIRST-YEAR STUDENTS' STRATEGIES DEVELOPMENT (M - MEAN VALUE; S.D. - STANDARD DEVIATION)

\begin{tabular}{|l|l|l|l|}
\hline \multirow{2}{*}{ Scales } & \multicolumn{2}{c|}{ Sampling values } & \multicolumn{1}{c|}{ Extent } \\
\cline { 2 - 4 } & \multicolumn{1}{c|}{$\boldsymbol{M}$} & \multicolumn{1}{c|}{ S.D. } & \multicolumn{1}{c|}{$\boldsymbol{M}$} \\
Inconsistency analysis & 3.53 & 1.372 & Average \\
\hline Forecasting & 4.02 & 1.269 & Average \\
Goal setting & 3.49 & 1.514 & Average \\
Planning & 3.29 & 1.560 & average \\
\hline Quality assessment & 2.80 & 1.268 & average \\
Decision-making & 3.55 & 1.501 & Above average \\
\hline Self-control & 3.40 & 1.180 & average \\
\hline Adjustment & 2.95 & 1.026 & average \\
$\begin{array}{l}\text { Overall self-management } \\
\text { capacity }\end{array}$ & 27.02 & 6.19 & Above average \\
\hline
\end{tabular}

To conclude, most of the results on specific selfmanagement strategies correspond the average intensity, while above the average was identified on the 'decisionmaking' strategy, which speaks of the fact that this particial operation is actualized by the first-year students best of all.

Units of the upper part of the list, according to Peisakhov's comments, relate to the initial strategies of selfmanagement in the terms of specific efforts (preparing for activities); the net index on the first four strategies (14.3) is higher than on the rest four strategies (12.7) accompanying achievement of the efforts. Therefore, it is expedient to advise the first-year students promoting their strategies that control actualization of efforts and assessing the outcomes.

The comparison of the extent of self management strategies' formation by students with higher and lower performance has identified substantial differences on three self-management strategies and on the overall performance "Table III".

TABLE III. STATISTICS ON THE SELF-MANAGEMENT OF DIFFERENT LEVEL STUDENT PERFORMANCE (M - MEAN VALUE, S.D. - STANDARD DEVIATION; F-TEST - FISHER TEST; P - SignifiCANCE POINT)

\begin{tabular}{|l|c|c|c|c|l|}
\hline \multirow{2}{*}{ SM phase } & \multicolumn{2}{|c|}{$\begin{array}{c}\text { Higher student } \\
\text { performance }\end{array}$} & \multicolumn{2}{c|}{$\begin{array}{c}\text { Lower student } \\
\text { performance }\end{array}$} & \multirow{2}{*}{ F-test } \\
\cline { 2 - 5 } & $\boldsymbol{M}$ & S.D. & $\boldsymbol{M}$ & $\boldsymbol{S} . \boldsymbol{D}$. & \\
\hline Forecasting & 4.53 & 1.042 & 3.40 & 1.258 & 8.617 \\
\hline Planning & 3.57 & 1.501 & 2.96 & 1.594 & 3.796 \\
\hline Quality assessment & 3.03 & 1.351 & 2.52 & 1.122 & 4.193 \\
\hline $\begin{array}{l}\text { General self- } \\
\text { management capacity }\end{array}$ & \begin{tabular}{l}
79.0 \\
\hline
\end{tabular} & 5.948 & $\begin{array}{l}24.5 \\
6\end{array}$ & 5.650 & 11.352 \\
\hline
\end{tabular}

Thuswise, the consistent differences between the students with higher performance and lower performance have been identified on the following strategies: forecasting, planning, control estimate and the general self-management capacity.

Statistically significant lower results on the said scores are typical of the students with lower performance.

\section{The SELF-MANAgEMENT STRATEgy PREDICTOR FUNCTION STUDY}

Thus, it has been identified that the self-management strategy 'forecasting' presents the performance predictor for first-year students of the economic faculty of a classic university "Table IV".

TABle IV. COEFFICIENT OF REgRESSION MODEL FOR STUdENTS WITH DifFERENT PERFORMANCE LEVEL (1 - MoRE SUCCESSFUL, 2- LESS SUCCESSFUL).

\begin{tabular}{|c|c|c|c|c|c|c|c|}
\hline \multirow{2}{*}{\multicolumn{2}{|c|}{ Pattern }} & \multicolumn{2}{|c|}{ Non-standard coefficient } & \multirow{3}{*}{$\begin{array}{c}\text { Standard coefficient . } \\
\text { beta }\end{array}$} & \multirow{2}{*}{$\mathbf{t}$} & \multirow{2}{*}{ Value } & \multirow{2}{*}{$\begin{array}{c}\text { Collinearity statistic } \\
\text { Allowance }\end{array}$} \\
\hline & & $\boldsymbol{B}$ & Statistic uncertainty & & & & \\
\hline 1 & (Invariable) & -0.168 & 0.205 & & -0.823 & 0.414 & \\
\hline & Forecasting & 0.178 & 0.049 & 0.449 & 3.656 & 0.001 & 1.000 \\
\hline 2 & (Invariable) & -0.765 & 0.294 & & -2.600 & 0.012 & \\
\hline & Forecasting & 0.170 & 0.046 & 0.430 & 3.700 & 0.001 & 1.003 \\
\hline
\end{tabular}




\section{CONCLUSION}

The students performance and their self-management capacity are closely interdependent. Students with high level of academic performance are demonstrating the overall high self-management capacity and better results on specific strategies-the ability to forecast, planning and quality assessment.

The 'forecasting' predictor function is independent of the level of student performance.

The hypothesis underlying this research has been verified-it has been empirically established that for Russian first-year students of the economic faculty the selfmanagement strategy 'forecasting' can be the predictor function in terms of their academic performance. The results of this study can have practical application in the psychological and pedagogical support of students' training, as well as in the process of their counseling in order to achieve the best academic performance.

\section{REFERENCES}

[1] Y.D. Yankulova, "Cognitive personal determinants of self-regulated learning in the academic environment", extended abstract of dissertation for a Doctor of Science degree, Sophia, Sofia University St. Kliment Ohridski, 2014, p. 39.

[2] H. Le, A. Casillas, S.|B. Robbins, et al., "Motivational and skills, social, and self-management predictors of college outcomes: Constructing the student readiness inventory.", Educational and Psychological Measurement, 65(3), 2005, pp. 482-508.

[3] E.I. Petanova, E.P. Bakhcheeva, Self-management capacity of psychology students as a prerequisite of professional success / Professional and personal development of future specialist: Collection of articles, SPb.: Saint-Petersburg University Press, 2012, pp. 93-110.

[4] N.M. Peisakhov, M.N. Shevtsov, "Practical pshychology", Kazan, Kazan University Press, 1991, p. 120.

[5] N.A. Vagapova, "Structural features of self-management psychological mechanism (based on academic and professional activities)", thesis for PhD dergee, Kazan, 1998.

[6] G.Sh. Gabreeva, Menta state self-management, KGU Press, 1981, p. 63. 